\title{
SOP myasthenic crisis
}

\author{
Henning Stetefeld ${ }^{*}$ iD and Michael Schroeter
}

\begin{abstract}
Introduction: The overall prevalence of myasthenic crisis is quite low at 30/1 million inhabitants because myasthenia gravis is a rare disease per se. But it should be noted that $15-20 \%$ of patients with myasthenia gravis experience at least one crisis in their lives. Most often, the crisis occurs within the first 2 years of the disease or is even the first manifestation of a yet undiagnosed myasthenia gravis in up to $20 \%$.

Median duration of MC is about 2 weeks (median 12-14 days of ventilation) under sufficient treatment, but prolonged courses are not uncommon and often due to comorbidities and complications, so that about $20 \%$ are still mechanically ventilated after 1 month.

The lifetime risk of recurrence of a crisis is approx. 30\%. Data on mortality differ between about 2-5\% to even more than $16 \%$. Lethal outcomes are almost never caused by the crisis itself, but because comorbidities or complications eventually become limiting.

Definition: Myasthenic crisis (MC) is the life-threatening maximal manifestation of myasthenia gravis (MG) necessitating mechanical ventilation, supportive feeding and (neuro-)intensive care. Weakness may develop within minutes to days and encompass flaccid tetraparesis with immobility, severe dyspnea, respiratory insufficiency and aspiration. Globus events may be life threatening due to rapidly exhausting coughing and swallowing.

First steps: immediate measures: • Check and secure vital functions

\section{Comments: • not applicable}

Conclusion: The main symptom of (imminent) myasthenic crisis is the rapidly progressive weakness of the respiratory and bulbar muscles, which lead to a decompensation with aspiration and respiratory insufficiency. Clinical examination and clinical history should lead early to the diagnosis of MG with (impending) crisis. The detection of red flags and the dynamic deterioration of symptoms entail admission to the intensive care unit. Due to bulbar symptoms with aspiration and/or respiratory insufficency, early intubation to secure the airway is essential. Therapy includes symptomatic treatment with pyridostigmine or neostigmine and acute causal treatment by immunoadsorption/plasmapheresis or alternatively with immunoglobulins. If used early, intubation may still be prevented and clinical improvement can be achieved within a few days. At the same time, immunosuppression with corticosteroids and azathioprine should be initiated or optimized. For escalation rituximab is an option. The early diagnosis and consequent treatment of infections and other complications such as delirium influence the further course.
\end{abstract}

\section{Flow chart SOP myasthenic crisis}

Comments, Explanations, Additions (see footnotes in Figure 1)

1. In most cases, a crisis is preceded by a prodromal syndrome of several days or even weeks with new or aggravated myasthenic symptoms like bulbar and/or generalized, especially respiratory weakness. Typical symptoms to encounter are:

* Correspondence: henning.stetefeld@uk-koeln.de Department of Neurology, University of Cologne, Kerpener Str. 62, 50937 Cologne, Germany

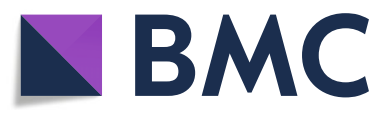

(c) The Author(s). 2019 Open Access This article is distributed under the terms of the Creative Commons Attribution 4.0 International License (http://creativecommons.org/licenses/by/4.0/), which permits unrestricted use, distribution, and reproduction in any medium, provided you give appropriate credit to the original author(s) and the source, provide a link to the Creative Commons license, and indicate if changes were made. The Creative Commons Public Domain Dedication waiver (http://creativecommons.org/publicdomain/zero/1.0/) applies to the data made available in this article, unless otherwise stated.
- ptosis increasing in the course of the day

- double vision especially at the end of the day

- difficulties to swallow

- ingestion, cough after eating, and frank aspiration

- leakage ("upward aspiration") of liquids and food in the nose during the act of swallowing

- fainting and failure of the voice during prolonged speech

- usually weakness of the anterior cervical musculature, with head drop 
progressive dysphagia, dyspnoe and activity-dependent weakness

Obtain history and symptoms (1)

- bulbar dysfunction: dysphagia, aphonic dysarthria, ptosis, diplopia?

- dyspnoe/orthopnoe?

- flaccid tetraparesis?

- precipiting factors: (bronchopulmonal) infection, medication?

- myasthenia gravis already diagnosed or first manifestation?

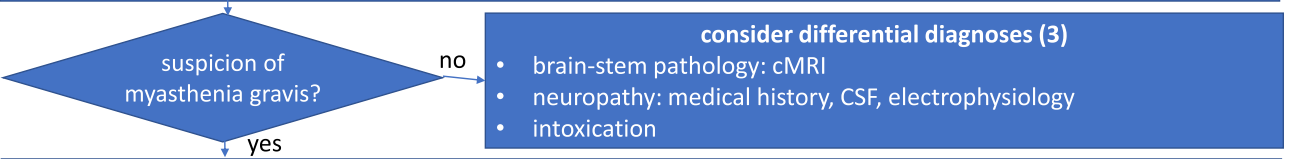

physical and neurological examination (2): QMG incl. vital capacity, MG-ADL

emergency blood test: blood gas analysis, blood-count, electrolytes, TSH, CRP, procalcitonine, urea, creatinine, liver enzymes, specific antibodies

Assess criteria for red flags (4)

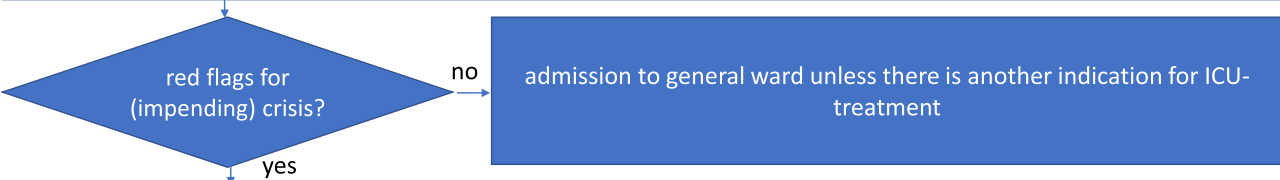

admission to ICU and monitoring (5)

- intensive care management: airway management, swallowing assessment, „,anti-delirium -bundle“

- QMG incl. vital capacity

- avoid and treat complications

eliminate precipitng factors

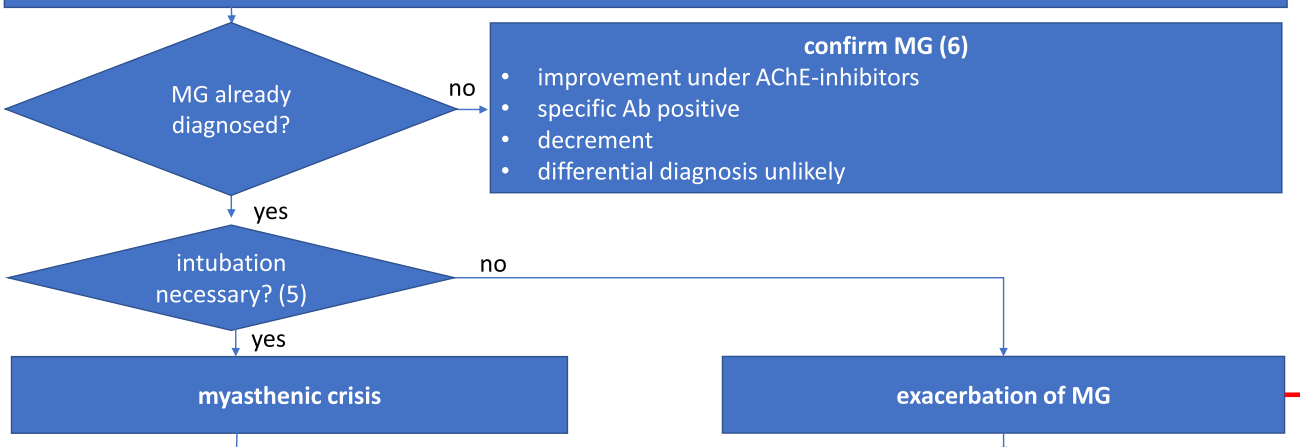

acute symptomatic therapy (7)

Pyridostigmine or Neostigmine po. / iv. vs. „drug holiday
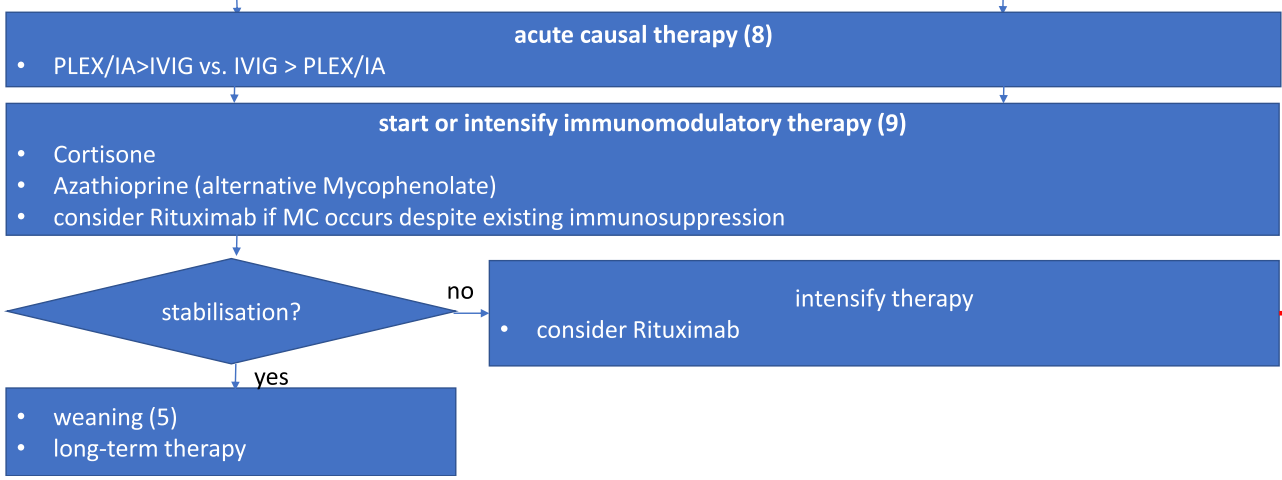

intensify therapy

consider Rituximab 
- breathing with the help of respiratory muscles, orthopnea

- very often pneumonia due to aspiration and signs of sepsis due to decreased ventilation and aspiration

Possible triggers of a crisis or unspecific preceding events are most likely:

- (bronchopulmonary) infections

- treatment with certain medications (see Table 1)

- increase or decrease of cortisone dose / errors in treatment of MG

2. Adding to medical history (trigger?, prodromal symptoms?, MG already known?) clinical evaluation of myasthenic symptoms (in particular bulbar symptoms and / or respiratory insufficiency) is most important. QMG and MG-ADL are most useful scoring systems to measure the severity of deficits and to monitor the clinical course of disease.

3. For any new muscular weakness associated with dysphagia and / or dyspnea or respiratory failure, myasthenia gravis or myasthenic crisis should always be considered in differential diagnosis. Other possible etiologies are listed in Table 2.

Even though the cholingergic crisis is rare today, due to intoxication with AchE-inhibitors the typical symptoms should still be known: muscarinic overstimulation causes miosis, bradycardia, diarrhea, salivation, warm and red skin and nicotinergic effects are crampi, muscle weakness, fasciculation. However, a differentiation between myasthenic crisis and cholinergic crisis is sometimes difficult (insensitive crisis). Then the probative administration of neostigmine or pyridostigmine as well as atropine under monitoring

Table 1 Medications which might worsen myasthenia gravis

\begin{tabular}{ll}
\hline Substance group & Example \\
\hline Steroids, high dose & $\begin{array}{l}\text { Dexamethasone, Triamcinolone } \\
\text { (also locally) }\end{array}$ \\
Gyrase inhibitors & Moxifloxacine \\
Macrolides & $\begin{array}{l}\text { Azithromycine, Clarithromycine, } \\
\text { Telithromycine }\end{array}$ \\
Lincomycins & Clindamycine \\
Tetracyclines & Doxycycline \\
non-Nifedipin-type & Verapamile \\
calcium antagonists & \\
Antipsychotics & Opipramole, Sulpiride \\
\hline
\end{tabular}

can help to differentiate the need for AchE-inhibitors or an overdose (also see point 6) [1-10].

4. Red flags for the impending $\mathrm{MC}$ are:

- febrile infection in the last 2 weeks treated with antibiotics

- "inverse aspiration": food and drink get into the nose during swallowing

- insufficient swallowing: coughing or clearing throat after swallowing

- insufficient coughing or coughing impulse

- aphonic dysarthria: typically weakness of phonation during speech with nasal pronunciation (rhinophonia aperta)

- "dropped head": head falls forward, fixed paresis of the head extensors

- "dropped chin": lower jaw drops after (longer) chewing

- new facial weakness

- vital capacity $<20 \mathrm{ml} / \mathrm{kg}$ body weight, (e.g., $<1500 \mathrm{ml}$ in men or $<1000 \mathrm{ml}$ in women)

\section{Red flags and dynamic symptom deterioration should lead to admission to an intensive care unit or intermediate care unit}

CAVE: In addition to aspiration with pneumonia and sepsis, acute life-threatening events occur due to dysphagia with bolus events or ingestion and/or due to respiratory weakness (eg, by coughing) with respiratory insufficiency and consequently hypoxic damage (asphyxia).

5. The patient with an impending crisis (see "red flags") should be monitored closely, which means a regular swallowing assessment and regular survey (e.g. every 4-6 h) of the QMG including vital capacity and blood gas analyzes as well as continuous measurement of oxygen saturation regarding respiratory decompensation. For this, admission to an ICU or at least IMC unit with neurologic competence is essential. Intensive care management also includes:

- swallowing assessment / dysphagia therapy (naso-gastric tube), FEES

- airway-management

- as long as there is no severe dysphagia and the respiratory situation seems compensated, noninvasive ventilation (NIV) may be considered in order to give the patient the necessary breather and possibly prevent intubation

- indication for intubation is based on static parameters (see Table 3), but there are no strict cut-off values as they might differ interindivually; more important are deterioration in blood- 
Table 2 Extract of possible differential diagnoses of myasthenia gravis and newly occurring and progressive dysphagia respectively

\begin{tabular}{|c|c|c|}
\hline Alternative etiology & Syndrome / diagnosis & Diagnostic \\
\hline \multirow[t]{4}{*}{ CNS } & \multirow{4}{*}{$\begin{array}{l}\text { brainstem-pathology: stroke, rhombencephalitis, } \\
\text { multiple sclerosis }\end{array}$} & - medical history \\
\hline & & $\begin{array}{l}\text { - additional symptoms correlating with } \\
\text { brainstem-syndrome }\end{array}$ \\
\hline & & $\cdot c M R$ \\
\hline & & - cerebral-spinal-fluid (CSF) \\
\hline \multirow[t]{5}{*}{ intoxication } & - cholinergic crisis & - medical history \\
\hline & o organophosphates & - muscarinergic and nicotinergic symptoms \\
\hline & o AchE-inhibitors & - improvement by atropine \\
\hline & - Botulism & - medical history \\
\hline & - Botulinum toxin overdose & - affection of cranial nerves with tonic pupils \\
\hline \multirow{3}{*}{$\begin{array}{l}\text { disturbance of the neuromuscular } \\
\text { transmission }\end{array}$} & - Lambert-Eaton-Syndrom & - antibodies (anti-VGKC-Ab) \\
\hline & - congenital Masthenia gravis & - medical history \\
\hline & & - electrophysiology (increment) \\
\hline \multirow[t]{5}{*}{ myopathy } & \multirow{2}{*}{$\begin{array}{l}\text { - endocrinopathy (hyperparathyreodism, } \\
\text { hypo/hyperthyreosis, hyperinsulinism, } \\
\text { M. Addison) }\end{array}$} & $\begin{array}{l}\text { - laboratory parameters: TSH, T3/4, CK, } \\
\text { potassium etc. }\end{array}$ \\
\hline & & - specific antibodies \\
\hline & • hypokaliaemia, & - medical history \\
\hline & - dermato/polymyositis, & - electrophysiology \\
\hline & - toxic/medication (statins, cortisone) & \\
\hline \multirow[t]{5}{*}{ polyneuropathy / polyradiculopathy } & - Guillain-Barré-Syndrome & $\cdot$ CSF \\
\hline & - Miller-Fisher-Syndrome & - antibodies (anti-gangliosid) \\
\hline & - intoxication & - medical history \\
\hline & - critical-illness-polyneuropathy & - loss of reflexes and sensory deficits \\
\hline & & - electrophysiology \\
\hline \multirow[t]{4}{*}{ motoneuron disease } & amyotrophic lateral sclerosis & - medical history \\
\hline & & - fasciculations, spastic paresis \\
\hline & & - electrophysiology \\
\hline & & $\cdot c M R I$ \\
\hline
\end{tabular}

gas-analysis and dynamics of the decrease in vital capacity as well as severe dysphagia or (silent) aspiration

- choose pressure-regulated ventilation

- weaning: episodes of spontaneous breathing with positive airway pressure (CPAP) in extended intervals in a structured manner

- extubation: stable and satisfactory ventilationrelated parameters (see Table 3), sufficient cough and adequate swallow at least for thickened liquid or mushy food
- consider early elective tracheotomy in prolonged crisis - eliminate and treat precipiting factors and complications like infection or electrolyte disturbances, consider the impact of comorbidities - delirium

- day-structuring activities, establish day-nightrhythm, physio- and ergotherapy ("anti-delirium bundle")

- lorazepam for anxious-agitated patients - if necessary: phenothiazine, haldol or lowpotency neuroleptics

Table 3 Parameters for bedside ventilation during myasthenic crisis [6]

\begin{tabular}{lllll}
\hline Criterion/indication & Normal & Intubation & Weaning & Extubation \\
\hline Vital capacity $(\mathrm{ml} / \mathrm{kg}$ body weight) & $>60$ & $<20$ & $>15$ & $>25$ \\
Negative airway pressure $\left(\mathrm{cm} \mathrm{H}_{2} \mathrm{O}\right)$ & $>70$ & $<30$ & $>20$ & $>40$ \\
Positive airway pressure $\left(\mathrm{cm} \mathrm{H}_{2} \mathrm{O}\right)$ & $>100$ & $<40$ & $>40$ & $>50$ \\
\hline
\end{tabular}


6. Since not all diagnostic steps can be taken during the acute situation, a further approach should be taken during parallel intensive care treatment to confirm the diagnosis of MG (crisis as first manifestation of the disease), to detect possible precipiting factors of the crisis, and to rule out differential diagnoses (see Table 2):

- electrophysiological examination:

- repetitive stimulation to detect decremental response

- exclusion of neuropathy (e.g., Gulliain-BarreSyndrome, Miller-Fisher-Syndrome, criticalillness-neuropathy) - exclusion of myopathy (e.g., rhabdomyolysis)

- laboratory: - blood-cell-count, electrolytes including potassium, TSH, CRP, procalcitonine, urea, creatinine, liver enzymes

- blood culture

- specific antibodies (anti-AChR-ab, antiMusk-ab etc.)

- imaging:

- chest X-ray: pneumonia?

- consider CT or MRI of chest regarding thymus pathology

- consider cMRI with Gd to rule out brainstem pathology

- pharmacologic testing:

- ex juvantibus AChE-inhibitors (former "tensilone test"): for example with neostigmine or pyridostigmine iv. (keep atropine ready as antidote!)

7. Therapy of $\mathrm{MC}$ and imminent $\mathrm{MC}$ is multidimensional including symptomatic acute treatment, causal acute treatment, initiation or modification of long-term immunosuppressive therapy and specialized intensive care management.

Symptomatic acute treatment:

${ }^{\circ}$ pyridostigmine (Mestinon ${ }^{\circ}$ ) p.o. 3-6x60mg, max. $540 \mathrm{mg} / \mathrm{d}$ or

- pyridostigmine iv. (equivalent: orally:parenterally $\sim 30: 1$ )

- $360 \mathrm{mg} / \mathrm{d}$ p.o. equals to $12 \mathrm{mg} / \mathrm{d}$ i.v., $\max .24$ $\mathrm{mg} / \mathrm{d}$

- bolus $1-3 \mathrm{mg}$ followed by $0.5-1 \mathrm{mg} / \mathrm{h}$ alternatively:

- neostigmine iv. (equivalent::

orally:parenterally $=\sim 80: 1$ )

- $360 \mathrm{mg} / \mathrm{d}$ Pyridostigmine p.o. $=4.5 \mathrm{mg} / \mathrm{d}$

neostigmine i.v.

- starting dose $6-12 \mathrm{mg} / 24 \mathrm{~h}$, adjust $0.2-0.8$

$\mathrm{mg} / \mathrm{h}$, bolus of $0.5 \mathrm{mg}$ possible

- atropine $0.5-1 \mathrm{mg}$ s. c. oder iv. against side effects (bronchial secretion)
- consider "drug-holiday" when intubated and not breathing spontaneously

8. Effects of causal acute therapy can be observed after a few days usually (see Table 4). Indication for each regime depends on whether there is a crisis or an exacerbation and on complications.

- plasma exchange (PLEX) or immunoadsorption (IA)

- first-line therapy of crisis

- 5-6 or even more treatments

- effect after a few days polyvalent immunglobulines (IVIG)

- first choice for exacerbation / imminent crisis

- $0.4 \mathrm{~g} / \mathrm{kg}$ body weight per day for 5 consecutive days or $1,5-2 \mathrm{~g} / \mathrm{kg}$ body weight (bw) for 2(-3)

days

- effect after a few days

9. Long term immunosuppressive therapy should be started also during crisis/exacerbation already although effects appear after several weeks (cortisone) or months. It contributes to long-term stabilization.

- cortisone

- effect after 1 month

- CAVE: "dip" with initial deterioration possible, the more critical the clinical situation the lower should be the starting dose!

- exacerbation:

- increasing dosage, for example

Prednisolone 10-20-40-60 mg/d

- increase weekly in order to avoid initial deterioration ("dip")

- decrease in similar steps but every 2-3 week intervals to $20 \mathrm{mg} / \mathrm{d}$, then choose longer intervals and smaller steps depending on clinical condition

- crisis (artifical ventilation):

- 100 mg Prednisolone

- reduce every 10 days by $10-20 \mathrm{mg}$ to 30 $\mathrm{mg} / \mathrm{d}$, thereafter at longer intervals and with decreasing dose steps

- azathioprine, started parallely with cortisone:

- start when septic conditions are ruled out

Table 4 Latency of myasthenia therapies

\begin{tabular}{ll}
\hline Therapy & Latency \\
\hline PLEX/IA & few days \\
IVIG & few days ("Dip" possible?) \\
Cortisone & $3-4$ weeks ("Dip" frequent!) \\
Azathioprine & $6-12$ months \\
Mycophenolate & $6-12$ months (???) \\
Rituximab & $2-3$ months \\
Thymektomy & months-years \\
\hline
\end{tabular}


- 1st week $50 \mathrm{mg} / \mathrm{d}$ - 2nd week $100 \mathrm{mg} / \mathrm{d}$ - 3rd week $150 \mathrm{mg} / \mathrm{d}$ or $2,5 \mathrm{mg} / \mathrm{kg}$ bw

- further dosage depends on laboratory parameters: 6-8 weeks after initiation absolute lymphocyte count should be $0,6-1,0 /$ nl while whole leucocyte count should be $>3,0 / \mathrm{nl}$ and transaminases less than 5-fold of upper limit - alternative (e.g. TPMT-deficiency): mycophenolate (MMF)

- in case of myasthenic crisis despite existing (and effectively ingested) immunosuppressive therapy: escalation with rituximab for both AChR-Ak positive and MuSK-Ak positive myasthenia

- several dosage schemes; e.g. $1 \mathrm{~g}$ rituximab given twice at 14-day intervals

- repeat after 1 year or after the CD19 positive cells have risen to the measurable range or after recurrence of symptoms

\section{Abbreviations}

ab: Antibody; AChE-inhibitor: Acetylcholin-esterase inhibitor;

AChR: Acetylcholin receptor; CMRI: Cranial magnet resonance tomography; CSF: Cerebrospinal fluid; FEES: Fiberoptic endoscopic evaluation of swallowing; IA: Immunoadsorption; IVIG: Immunglobulines; MC: Myasthenic crisis; MG: Myasthenia gravis; MMF: Mycophenolate mofetil; PLEX: Plasma exchange

\section{Acknowledgements}

Not applicable.

\section{Funding}

No funding.

Availability of data and materials

Not applicable.

\section{Authors' contributions}

HS and MS contributed equally to conception of the work, drafted the manuscript and approved submission.

\section{Ethics approval and consent to participate}

Not applicable.

\section{Consent for publication}

Not applicable.

\section{Competing interests}

$H$. Stetefeld declares that he has no competing interests.

M. Schroeter has received speaking fees from Alexion, Biogen, Genzyme/

Sanofi, Grifols, Miltenyi Biotec, Novartis.

\section{Publisher's Note}

Springer Nature remains neutral with regard to jurisdictional claims in published maps and institutional affiliations.

Received: 1 April 2019 Accepted: 16 April 2019

Published online: 29 July 2019

\section{References}

1. Wiendl, H. (federführend). Diagnostik und Therapie der myasthenia gravis und des Lambert-Eaton Syndroms. https://www.dgn.org/leitlinien/3005-II68-II-diagnostik-und-therapie-der-myasthenia-gravis-und-des-lambert-eatonsyndroms. Accessed 22 Mar 2019.
2. Meriggioli, M. N., \& Sanders, D. B. (2009). Autoimmune myasthenia gravis: Emerging clinical and biological heterogeneity. Lancet Neurology, 8, 475-490.

3. Lacomis, D. (2005). Myasthenic crisis. Neurocritical Care, 3, 189-194.

4. Alshekhlee, A., Miles, J. D., Katirji, B., et al. (2009). Incidence and mortality rates of myasthenia gravis and myasthenic crisis in US hospitals. Neurology, 72, 1548-1554.

5. Thomas, C. E., Mayer, S. A., Gungor, Y., et al. (1997). Myasthenic crisis: Clinical features, mortality, complications, and risk factors for prolonged intubation. Neurology, 48, 1253-1260.

6. Rabinstein, A. A. (2016). Noninvasive ventilation for neuromuscular respiratory failure: When to use and when to avoid. Current Opinion in Critical Care, 22, 94-91

7. Ramos-Fransi, A., Rojas-García, R., Segovia, S., Márquez-Infante, C., Pardo, J., Coll-Cantí, J., Jericó, I., Illa, I., Alberti Aguilo, M. A., Bataller Alberola, L. Berciano Blanco, J., Casasnovas Pons, C., Diaz-Manera, J., Fernandez Torron, M. R., Garcia Sobrino, T., Gomez Caravaca, M. T., Guerrero Sola, A., Gutierrez Gutierrez, G., Lopez de Munain Arregui, A., Martinez Pineiro, A., Mendoza Grimon, M. D., Munoz Blanco, J. L., Pelayo Negro, A. L., Querol, L., \& Sevilla Mantecon, T. (2015). Myasthenia gravis: Descriptive analysis of lifethreatening events in a recent nationwide registry. European Journal of Neurology, 22, 1056-1061.

8. Damian, M. S., Ben-Shlomo, Y., Howard, R., Bellotti, T., Harrison, D., Griggs, K., \& Rowan, K. (2013). The effect of secular trends and specialist neurocritical care on mortality for patients with intracerebral haemorrhage, myasthenia gravis and Guillain-Barré syndrome admitted to critical care : An analysis of the Intensive Care National Audit \& Research. Intensive Care Medicine, 39, 1405-1412

9. Sanders, D. B., Wolfe, G. I., Benatar, M., Evoli, A., Gilhus, N. E., Illa, I., Kuntz, N., Massey, J. M., Melms, A., Murai, H., Nicolle, M., Palace, J., Richman, D. P., Verschuuren, J., \& Narayanaswami, P. (2016). International consensus guidance for management of myasthenia gravis: Executive summary. Neurology, 87(4), 419-425.

10. Godoy, D. A., Mello, L. J., Masotti, L., et al. (2013). The myasthenic patient in crisis: An update of the management in Neurointensive care unit. Arquivos de Neuro-Psiquiatria, 71, 627-639.
Ready to submit your research? Choose BMC and benefit from:

- fast, convenient online submission

- thorough peer review by experienced researchers in your field

- rapid publication on acceptance

- support for research data, including large and complex data types

- gold Open Access which fosters wider collaboration and increased citations

- maximum visibility for your research: over $100 \mathrm{M}$ website views per year

At BMC, research is always in progress.

Learn more biomedcentral.com/submissions 